\title{
Reaction mechanism of trypsin-catalysed semisynthesis of human insulin studied by fast atom bombardment mass spectrometry
}

\author{
Keith Rose, Reto Stöcklin, Luc-Alain Savoy, \\ Pierre-Olivier Regamey, Robin E.Offord, \\ Pierre Vuagnat ${ }^{1}$ and Jan Markussen ${ }^{2}$
}

\begin{abstract}
Département de Biochimie Médicale, Centre Médical Universitaire, 1 rue Michel Servet, 1211 Geneva 4, 'Section de mathématiques, Université de Genève, 2-4 nue du Lièvre, 1211 Geneva 24 , Switzerland and ${ }^{2}$ Novo Nordisk A/S, Novo Allé, 2880 Bagsvaerd, Denmark
\end{abstract}

The production of semisynthetic human insulin for therapeutic purposes is of considerable importance. During trypsin-catalysed transformation of pig insulin into an ester of insulin of human sequence, the alanyl residue at position $B^{30}$ is removed and replaced with an esterified residue of threonine. We have carried out this transformation in a medium enriched in ${ }^{18} \mathrm{OH}_{2}$ and studied the product by MS. In contrast to a previous report, we find that incorporation of label into the $\mathrm{B}^{29}-\mathrm{B}^{30}$ peptide bond occurs during the transformation with threonine methyl ester in aqueous $N, N$-dimethylacetamide. Quantitative data are presented and the implications of these findings are discussed.

Key words: insulin/mass spectrometry/mechanism/semisynthesis

\section{Introduction}

The production of insulin of human sequence on an industrial scale is one of the successes of modern biotechnology. In the process used to make the majority of clinical-grade human insulin, pig insulin is transformed into the methyl ester of insulin of human sequence in a reaction catalysed by trypsin. During the trypsincatalysed transformation, the alanyl residue at position $\mathrm{B}^{30}$ of pig insulin is removed and replaced by a methyl-esterified residue of threonine (Scheme 1). The presence of the ester function, necessary if high yields are to be obtained in the transformation, also permits separation of the product from substrate by ion exchange chromatography, whereupon semisynthetic human insulin is generated by saponification of the ester. A key step in the production process is the trypsin-catalysed transformation. For this transformation, three extreme mechanistic cases have been discussed (Rose et al., 1984; and Scheme 1): (i) the reaction proceeds via formation of an acyl-enzyme intermediate which is aminolysed by threonine ester to give product without prior hydrolysis to des-Ala- $\mathrm{B}^{30}$-insulin; (ii) pig insulin is hydrolysed to des-Ala- $\mathrm{B}^{30}$-insulin, which then undergoes immediate coupling to give product; (iii) pig insulin, and thereafter acyl-enzyme intermediate, is hydrolysed reversibly to desAla- $\mathrm{B}^{30}$-insulin, and on average only after many cycles of acyl-enzyme intermediate $\rightarrow$ des-Ala- $\mathrm{B}^{30}$-insulin is the acylenzyme intermediate aminolysed to product. These three mechanisms may be distinguished by measuring the incorporation of labelled oxygen into product during a reaction carried out in a medium enriched with a stable isotope of oxygen. Mechanism (i) would not lead to any incorporation of label. Mechanism (ii) would lead to a maximum of $\sim 50 \%$ incorporation of label from the medium since the labelled oxygen atom incorporated on hydrolysis is one of two, and one is lost on subsequent product formation. Mechanism (iii) would lead to incorporation of label to an abundance similar to that existing in the medium. (Similar, but not identical because of kinetic and thermodynamic isotope effects; these can be very large in the case of isotopes of hydrogen but are small in the case of isotopes of the much heavier oxygen.)

Two previous studies have addressed this mechanistic question. The study of Markussen and Schaumburg (1983), using ${ }^{17} \mathrm{O}$ and NMR spectroscopy, seemed to support mechanism (i) since the authors reported that no incorporation of label into product occurred. The study of Rose et al. (1984), using ${ }^{18} \mathrm{O}$ and MS, supported mechanism (iii), since these authors found that extensive incorporation of label occurred. However, different experimental conditions were examined in this latter study [higher organic solvent concentration, butane-1,4-diol in place of $N, N$ dimethylacetamide, $\mathrm{H}-\mathrm{Thr}(t-\mathrm{Bu})-\mathrm{O}-t-\mathrm{Bu}$ in place of $\mathrm{H}-\mathrm{Thr}-\mathrm{OMe}$, and bovine trypsin in place of porcine trypsin].

In view of the conflicting results of the two studies and of kinetic evidence throwing doubt on the NMR study (Markussen, 1987), we decided to reinvestigate the transformation which occurs in aqueous dimethylacetamide with $\mathrm{H}-\mathrm{Thr}-\mathrm{OMe}$ as nucleophile and porcine trypsin as catalyst, which are the conditions used industrially.

\section{Materials and methods}

Human insulin methyl ester (zinc form), pig insulin (monocomponent grade, zinc form) and crystalline $\mathrm{H}-\mathrm{Thr}$-OMe free base were the products of Novo Industri, Denmark. Porcine trypsin and ${ }^{18} \mathrm{OH}_{2}$ (97\% atomic abundance, normalized) were obtained from Sigma Chemical Co. and MSD Isotopes (Montreal) respectively. Pentadeutero-L-threonine ( $98 \% \mathrm{D}$, unlabile protons) was obtained from CEA, Gif-sur-Yvette, France, and was converted into $\mathrm{H}-\left[{ }^{2} \mathrm{H}_{5}\right]-\mathrm{Thr}$-OMe free base by Novo-Nordisk, Bagsvaerd, Denmark. All other reagents and solvents of analytical grade, or better, were obtained from commercial sources, and were used without further purification.

\section{Transformation}

The exact conditions of Markussen and Schaumburg (1983) were used, except that ${ }^{18} \mathrm{O}$-enriched water replaced the water used in their experiment. All tubes were kept sealed with several layers of sealing film, except during addition and removal of contents. To $10 \mathrm{mg}$ pig insulin (and to $10 \mathrm{mg}$ human insulin methyl ester in a separate $6 \times 30 \mathrm{~mm}$ glass tube) was added $50 \mu \mathrm{l} 10 \mathrm{M}$ acetic acid made by mixing $115 \mu \mathrm{l} 100 \%$ acetic acid with $86 \mu \mathrm{l}^{18} \mathrm{OH}_{2}$. To these solutions were added $130 \mu \mathrm{l}$ of a solution of $\mathrm{H}$-Thr-OMe (204.8 $\mathrm{mg}$ in $1 \mathrm{ml} N, N$-dimethylacetamide) and the temperature was lowered to $12^{\circ} \mathrm{C}$. Porcine trypsin $(3.5 \mathrm{mg})$ was dissolved in $50 \mu \mathrm{l}$ calcium acetate solution [0.69 $\mathrm{mg} \mathrm{Ca}(\mathrm{OAc})_{2}$ in $82 \mu \mathrm{l}$ ${ }^{18} \mathrm{OH}_{2}$ ] and kept on ice for $10 \mathrm{~min}$. To both samples $20 \mu \mathrm{l}$ trypsin solution was added under vortex mixing and the tubes were set aside at $12^{\circ} \mathrm{C}$. Although perfectly soluble, the contents were mixed from time to time to ensure homogeneity. Samples $(20 \mu$ l) were withdrawn for analysis after $0,1,2,4,8,16,24$ and $48 \mathrm{~h}$. Time zero was counted as the moment when the trypsin solution was added, and the first aliquot was withdrawn within 


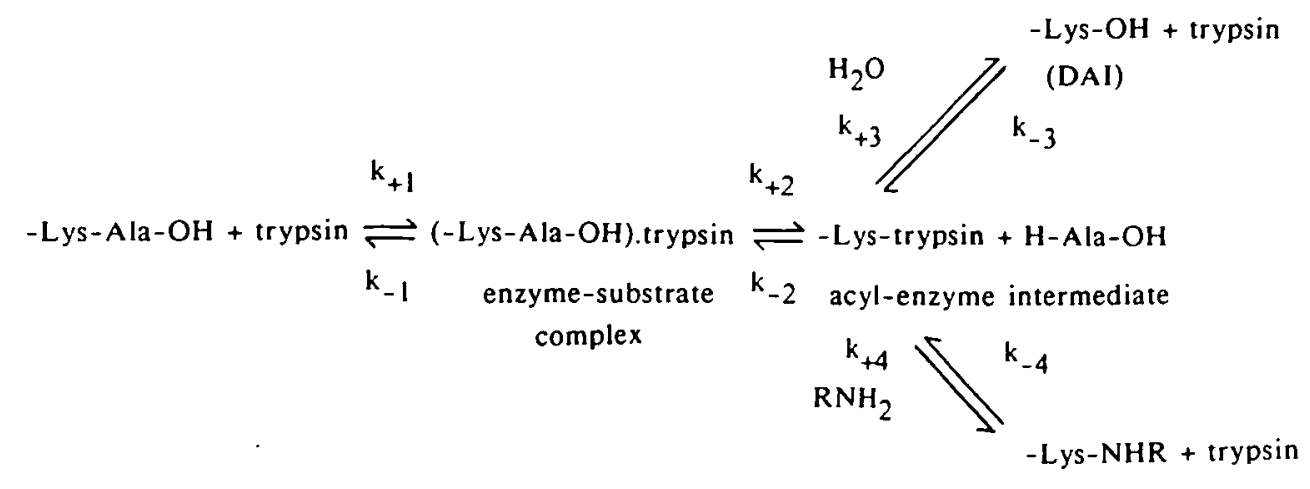

Aminolysis

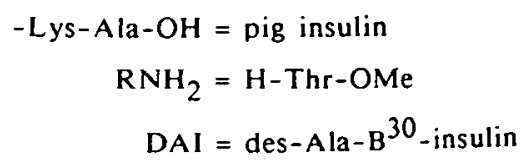

Scheme 1. Partial reaction scheme for the trypsin-catalysed transformation of pig insulin into an ester of insulin of human sequence (modified from Rose $e t$ al., 1984).

2 min of this addition. Immediately upon removal, each aliquot was treated with $200 \mu \mathrm{l}$ acetone to precipitate protein and stop the reaction. The precipitate was sedimented by centrifugation and, after removal of the supernatant, was washed by resuspension with two more $200 \mu$ l portions of acetone before being dried under vacuum.

Similar experiments, at reduced scale, were performed using $\mathrm{H}-\left[{ }^{2} \mathrm{H}_{5}\right]$-Thr-OMe in place of $\mathrm{H}$-Thr-OMe.

Analysis of coupling yield

Each of the 16 precipitates was dissolved in $200 \mu \mathrm{l} 0.1 \%$ trifluoroacetic acid. A small portion $(4 \mu \mathrm{l})$ was removed, diluted into $100 \mu \mathrm{l}$ of the same solvent and a $30 \mu \mathrm{l}$ aliquot analysed by reversed-phase HPLC. HPLC was performed using equipment from Waters Associates (M6000A and M45 pumps, Wisp 710B automatic injector, Model 440 absorbance detector and an extended wavelength module). The column was $250 \times 4 \mathrm{~mm}$ diameter packed with Nucleosil C8 $5 \mu \mathrm{m} 300 \AA$ particles (Machery Nagel) and operated at a flow rate of $0.6 \mathrm{ml} / \mathrm{min}$. Solvent A was $1 \mathrm{~g}$ trifluoroacetic acid (Pierce) added to 11 water (MilliQ system). Solvent B was prepared by adding $1 \mathrm{~g}$ trifluoroacetic acid to $100 \mathrm{ml}$ water and making up to $1 \mathrm{l}$ with acetonitrile (Lichrosolv, Merck). The column was equilibrated with $30 \%$ solvent $B$ prior to sample injection. These conditions were maintained for $5 \mathrm{~min}$ after injection, whereupon a linear gradient $(0.5 \% \mathrm{~B} / \mathrm{min})$ was initiated to $50 \% \mathrm{~B}$. After $5 \mathrm{~min}$ at $50 \% \mathrm{~B}$, the column was brought back to $30 \% \mathrm{~B}$ over $5 \mathrm{~min}$ and equilibrated for $15 \mathrm{~min}$ prior to the next injection. Effluent was monitored at $214 \mathrm{~nm}$.

\section{Sample preparation for mass spectrometry}

Trypsin was removed from samples by HPLC under conditions used for analysis (see above). For this purpose, $180 \mu l$ of the remaining $196 \mu \mathrm{l}$ of each sample was injected and the broad peak due to insulin, des-Ala-B30-insulin and human insulin methyl ester (unseparated from each other at this high loading) was collected (retention time 27-31 min), well separated from trypsin (retention time $41-48 \mathrm{~min}$ ). Solvent was removed in a vaccum centrifuge (Speedvac, Savant). Samples were resuspended in water and redried to remove residual trifluoroacetic acid. Each sample was then dissolved in $800 \mu \mathrm{l}$ ammonium bicarbonate solution $(1 \%, w / v)$. To $400 \mu \mathrm{l}$ of each sample was added $9 \mu \mathrm{l}$ of a solution of Staphylococcus aureus V8 protease $(1 \mathrm{mg} / \mathrm{ml}$ in water) and the tubes incubated at $37^{\circ} \mathrm{C}$ for $6 \mathrm{~h}$. After drying in the vacuum centrifuge, samples were taken up in $10 \mu \mathrm{l} 0.1 \%$ trifluoroacetic acid and analysed by fast atom bombardment mass spectroscopy (FAB/MS). Analysis by $\mathrm{FAB} / \mathrm{MS}$ in positive ion mode was performed as previously described (Savoy et al., $1988 \mathrm{a}, \mathrm{b})$. In order to obtain high precision in the measurement of isotopic abundance, each sample was analysed twice and the peptide originating from the C-terminal region of the $\mathrm{B}$ chain (H-Arg-Gly-Phe-Phe-Tyr-Thr-Pro-Lys-Thr-OMe) was on both occasions studied by taking 16 spectra over the molecular ion region and averaging the data.

\section{Results and discussion}

The yield of the trypsin-catalysed transformation of pig insulin into an ester of human insulin is represented graphically as a function of time in Figure 1. A yield of $93 \%$ is observed after $24 \mathrm{~h}$, and this rises to $94 \%$ after a further $24 \mathrm{~h}$. These results are in good agreement with the yield of $92 \%$ after $24 \mathrm{~h}$ reported previously (Markussen and Schaumburg, 1983).

In contrast with that previous study, however, incorporation of labelled oxygen into the $\mathrm{C}$-terminal region of the $\mathrm{B}$ chain (H-Arg-Gly-Phe-Phe-Tyr-Thr-Pro-Lys-Thr-OMe) was found to be extensive. In a previous similar study, the site of incorporation was shown to be the $\mathrm{B}^{29}-\mathrm{B}^{30}$ peptide bond (Rose et al., 1984), as expected from Scheme 1. Incorporation of ${ }^{18} \mathrm{O}$ is shown as a function of time in Figure 2, for both the reaction with pig insulin as substrate and the control reaction with human insulin methyl ester as substrate. In the case of pig insulin as substrate, the relatively small amount of product formed during the first hour of reaction shows a high degree of incorporation of label, and this degree of incorporation rises rapidly to reach a plateau of $>85 \%$. The slight fall occurring towards the end of the experiment may be due to ingress of unlabelled moisture into the cooled reaction tube during the removal of aliquots. 


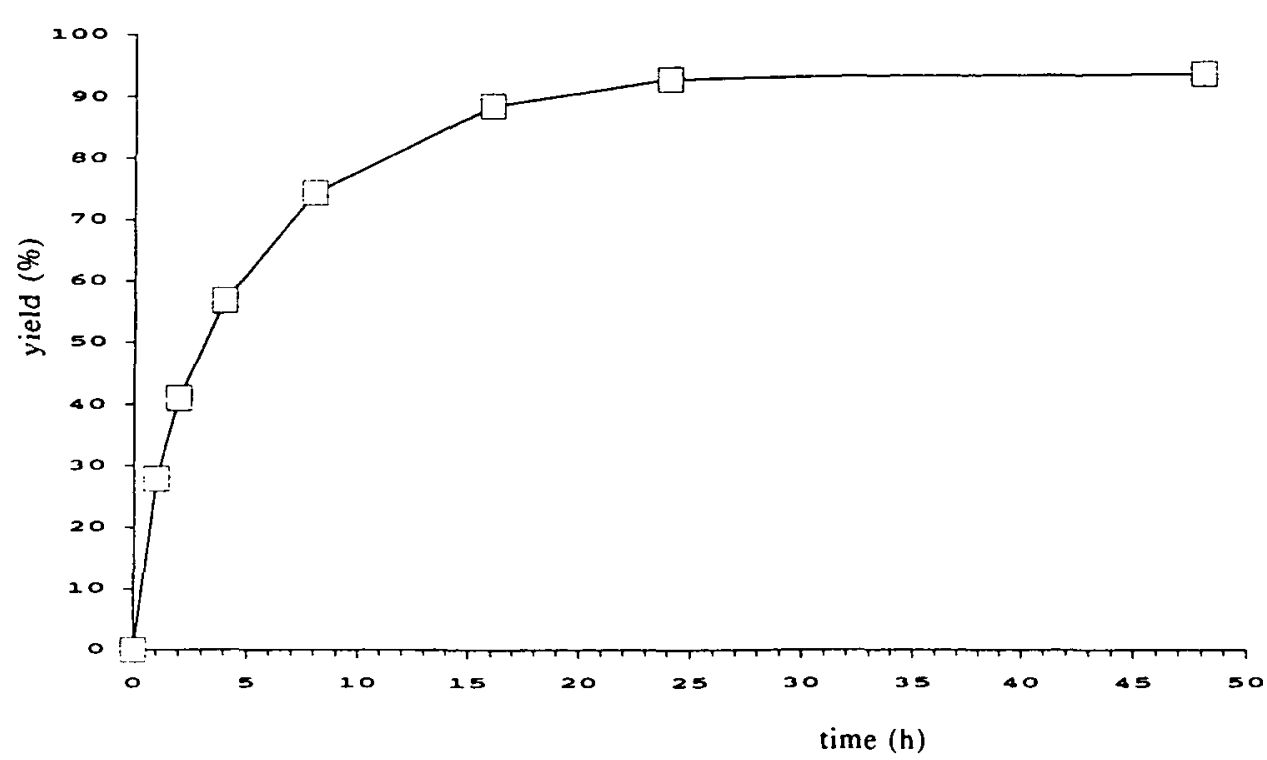

Fig. 1. Graph showing yield of human insulin methyl ester as a function of time. Reaction conditions are given in Materials and methods.

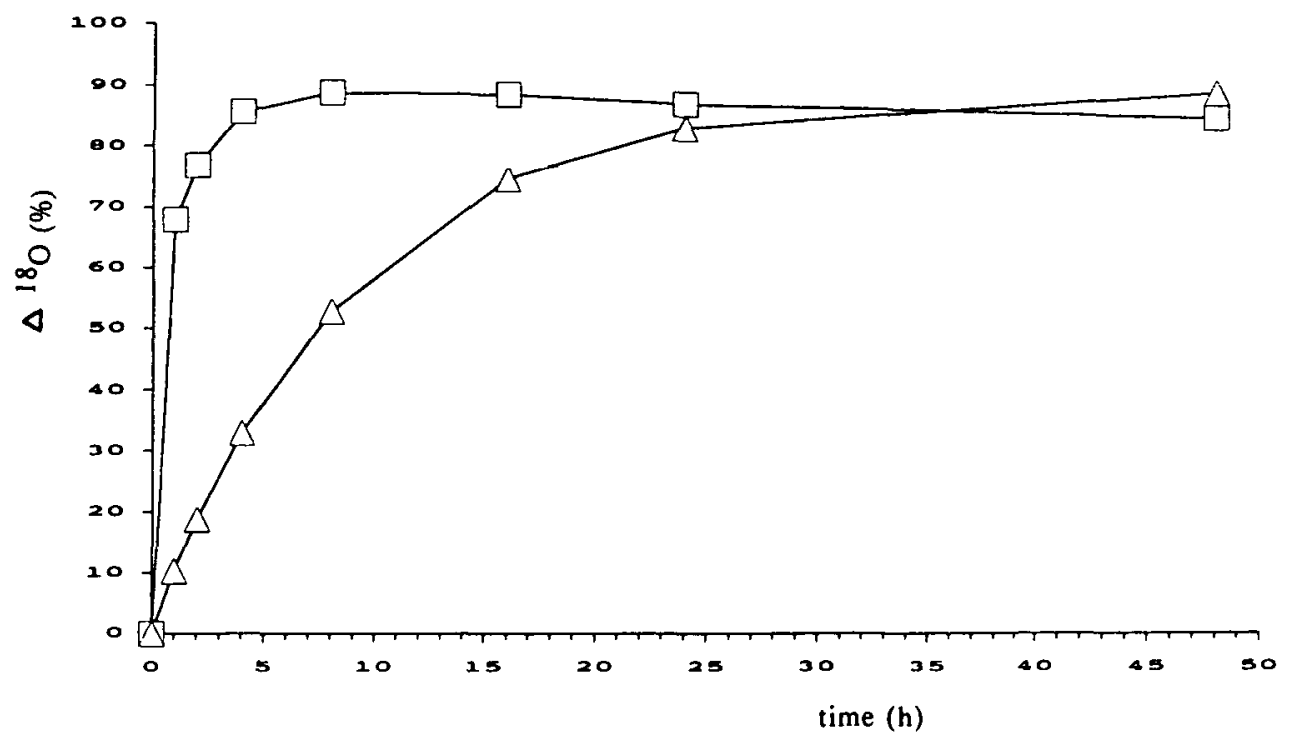

Fig. 2. Graph showing degree of incorporation of ${ }^{18} \mathrm{O}$ into the $\mathrm{B}^{29}-\mathrm{B}^{30}$ peptide bond of human insulin methyl ester as a function of time. $\square$, Reaction using pig insulin as substrate; $\triangle$, control reaction using human insulin methyl ester as substrate. Standard error of the mean (16 measurements) was $<1 \%$ in all cases.

Human insulin methyl ester, the product of the reaction between pig insulin and $\mathrm{H}$-Thr-OMe, is itself a substrate for trypsin. Under the conditions of our experiment, Thr-OMe at the $C$ terminus of the B chain is continually replaced by Thr-OMe from solution. Figure 2 shows that, during this process, label is incorporated into the $\mathrm{B}^{29}-\mathrm{B}^{30}$ peptide bond. The initial rate of incorporation of label in the control experiment (Figure 2) is considerably slower than both the coupling reaction (Figure 1) and the rate of incorporation of label into product during the transformation of pig insulin (Figure 2). We can thus be sure that the incorporation of label observed during the transformation of pig insulin is not simply due to incorporation into product once formed.

None the less, it is possible that, in addition to aminolysis after incorporation, some aminolysis of human insulin methyl ester occurs without incorporation of ${ }^{18} \mathrm{O}$. Such aminolysis without incorporation of label would be invisible to us, since there would be no change in HPLC or mass spectrometric properties. To investigate this possibility we repeated the above experiments using $\mathrm{H}-\left[{ }^{2} \mathrm{H}_{5}\right]-\mathrm{Thr}-\mathrm{OMe}$ in place of $\mathrm{H}-\mathrm{Thr}-\mathrm{OMe}$.

In the case of human insulin methyl ester, aminolysis of this substrate, initially unlabelled, was visible as a mass increase of 5 atomic mass units where not accompanied by incorporation of ${ }^{18} \mathrm{O}$, and as an increase of 7 mass units where incorporation of ${ }^{18} \mathrm{O}$ occurred. The proportion of mass-shifted material in the spectrum permitted the total degree of aminolysis to be calculated: 19,32 and $83 \%$ after 1,2 and $8 \mathrm{~h}$ respectively. Comparison with the data in Figures 1 and 2 shows that the total rate of aminolysis is comparable with the rate of reaction of pig insulin (Figure 1) and a little less than twice as fast as the rate of incorporation of ${ }^{18} \mathrm{O}$ shown in Figure 2 . It must not be forgotten that, after incorporation of an ${ }^{18} \mathrm{O}$ atom by hydrolysis, it has $-50 \%$ probability of being expelled upon peptide bond formation and so, if direct aminolysis and hydrolysis-coupling (see Scheme 1) 
occurred at equal rates, the initial product distribution would show only $25 \%$ (and not $50 \%$ ) incorporation of ${ }^{18} \mathrm{O}$. We may therefore deduce that aminolysis can and does occur without incorporation of ${ }^{18} \mathrm{O}$, although for the majority of molecules there is incorporation of ${ }^{18} \mathrm{O}$. This deduction is supported by the mass spectra obtained in the experiment just described, where $\mathrm{H}-\left[{ }^{2} \mathrm{H}_{5}\right]-\mathrm{Thr}-\mathrm{OMe}$ was used in place of $\mathrm{H}$-Thr-OMe. At all time points (except of course time zero, when there was no product at all) and for both pig insulin and human insulin methyl ester as substrate, the signal peak due to product having incorporated ${ }^{18} \mathrm{O}$ (mass shifted by 7 mass units due to the five deuterium atoms and one ${ }^{18} \mathrm{O}$ atom) was more intense (by a factor of between 1.03 and 2.6, depending on substrate and time point) than that due to product not having incorporated ${ }^{18} \mathrm{O}$ (and therefore mass shifted by only 5 mass units due to the five deuterium atoms).

\section{Conclusions}

The present study shows that, during the trypsin-catalysed transformation of pig insulin into an ester of insulin of human sequence, labelled oxygen is rapidly incorporated from the medium into the $\mathrm{B}^{29}-\mathrm{B}^{30}$ peptide bond. None the less, aminolysis of the acyl enzyme intermediate may occur without hydrolysis for a small proportion of molecules. For the majority, mechanism (iii) is followed whereby pig insulin, and thereafter acyl-enzyme intermediate, is hydrolysed reversibly to des-Ala- ${ }^{30}$-insulin, and on average only after several cycles of acyl-enzyme intermediate $\rightarrow$ des-Ala- $\mathrm{B}^{30}$-insulin is the acyl-enzyme intermediate aminolysed to product. $A$ better understanding of reverse proteolysis should permit further progress in the field of enzymic activation of polypeptide chains (Rose et al., 1988, 1989; Proudfoot et al., 1989).

\section{Acknowledgements}

We thank the Fonds National de la Recherche Scientifique, the Stanley Thomas Johnson Foundation, the Luzerna Krebsliga, the Ligue Suisse contre le Cancer and the Schmidheiny Foundation for financial support.

\section{References}

Markussen,J. (1987) Human Insulin by Tryptic Transpeptidation of Porcine Insulin and Biosynthetic Precursors. MTP Press, Lancaster.

Markussen,J. and Schaumburg,K. (1983) In Blaha,K. and Malon,P. (eds), Peptides 1982. W. de Gruyter, Berlin and New York, pp. 387-394.

Proudfoot,A.E.I., Rose,K. and Wallace,C.J.A. (1989) J. Biol. Chem., 264, 8764-8770.

Rose,K., Gladstone,J. and Offord,R.E. (1984) Biochem. J., 220, 189-196.

Rose,K., Herrero,C., Proudfoot,A.E.I., Offord,R.E. and Wallace,C.J.A. (1988) Biochem. J., 249, 83-88.

Rose,K., Jones,R.M.L., Sundaram,G. and Offord,R.E. (1989) In Jung,G. and Bayer,E. (eds), Peptides 1988. W. de Gruyter, Berlin and New York, pp. $274-276$.

Savoy,L.-A., Jones,R.M.L., Pochon,S., Davies,J.G., Muir,A.V., Offord,R.E. and Rose,K. (1988a) Biochem. J., 249, 215-222.

Savoy,L.-A., Vuagnat,P., Rose,K., Halstrom,J., Jørgensen,K.H. and Kovacs,K. (1988b) Protein Engng, 2, 313-315.

Received on August 30, 1990; accepted on December 24, 1990 